\title{
Public Health Workforce
}

\section{Future directions for the Bulletin}

\author{
D. Lynne Madden ${ }^{\mathrm{A}, \mathrm{C}}$, Megan E. Black ${ }^{\mathrm{A}}$, Carlie-Jane Naylor ${ }^{\mathrm{A}}$ and Richard Hecker \\ ${ }^{\mathrm{A}} N S W$ Public Health Bulletin, NSW Department of Health \\ ${ }^{\mathrm{B}}$ CSIRO PUBLISHING \\ ${ }^{\mathrm{C} C o r r e s p o n d i n g ~ a u t h o r . E m a i l: ~ l y n n e . m a d d e n @ d o h . h e a l t h . n s w . g o v . a u ~}$
}

We are very pleased to present with this issue a refreshed new look for the NSW Public Health Bulletin. This issue is also the first to be published through CSIRO PUBLISHING whose editorial and design team have worked with the Bulletin editorial team to develop this design, as well as the new website. These changes have been informed by surveys of the Bulletin readership, current practice in scientific journal publication and considerations of environmental sustainability.

New features for the publication include:

- An expanded table of contents that will appear as the back page of the issue. Each article title will be accompanied by a one-sentence description of the content.

- Contact details for the corresponding author and capacity for multiple affiliations for authors.

- Updated style of language to be aligned with current scientific usage.

The Bulletin has a new enhanced website located at http://www.publish.csiro.au/journals/phb. The NSW Health website will contain links to this site. There will be a transition period during which both the current Bulletin website and the new website will operate. The new production process will see the PDF and HTML versions of the Bulletin uploaded onto the new website in advance of the distribution of the printed copy.

The website has many new features:

- Readers can subscribe to an email notification system ('early alert') for new issues as they are uploaded to the Bulletin's website. The early alert provides readers with the contents of the issue and links to the articles.

- Reference lists cited by authors in the Bulletin will be linked to each cited paper if that paper is available on the Internet. This facility provides readers with immediate access to the evidence cited by authors.

- A 'most read' page to identify the most downloaded papers in the journal.

- A dedicated page for the special issues.

- An annual index of reviewers.

Several new resources have been developed and these are available through the website. For reviewers there is now a 'reviewer report form' that will provide a structure for reviewers to provide comments to both the editor and to the authors. This form is currently being piloted and we welcome feedback from reviewers who use it. For authors there are updated guidelines to publishing in the Bulletin. In coming weeks we hope to have a new resource that provides guidance on how to develop easy-to-read graphs and figures, based on the Better Health Graphs publication. ${ }^{1}$

Regarding sustainability, the Bulletin will be printed on archival quality chlorine-free paper using vegetable-based inks. The 'green' printer selected actively minimises waste through recycling all printing plates, offcut papers, and printing-related chemicals.

CSIRO PUBLISHING will manage the publication of the Bulletin - that is the production of the printed and electronic formats. The Bulletin editorial team assisted by a new Editorial Committee, remains responsible for the strategic direction, the management of the peer-review of articles, the selection of articles for publication, coordination of special issues and the content of the website.

Public health is a complex and evolving field and effective practice requires the integration and use of evidence. We would therefore like to encourage new and existing authors to continue to submit articles that describe their work to the 
Bulletin. We hope that the new production process will improve the Bulletin's timeliness, enable authors to reach a wider audience, give messages in the Bulletin greater penetration, and link readers to the broad public health literature. We look forward to receiving your comments about any of these new features.

\section{References}

1. Centre for Epidemiology and Research and Hunter Valley Research Foundation. Better Health Graphs (Volume 1): A report of an experimental study of interventions for improving graph comprehension. Sydney: NSW Department of Health, 2006.

\section{EDITORIAL}

\section{Strengthening learning opportunities to promote the capacity of the public health workforce}

\section{Lynne Madden}

Editor, NSW Public Health Bulletin.

Public Health Training and Development Branch, NSW Department of Health.

Email:lynne.madden@doh.health.nsw.gov.au

A skilled workforce is the major strategic resource for any industry. The articles in this issue propose ways to provide effective and accessible learning opportunities for the public health workforce in NSW and consider the potential contribution of standards to monitor population health practice including sustaining workforce capacity.

Problem solving skills in complex situations are particularly valued by health services and we need to develop this ability within the public health workforce. Research by Breen for the UK National Health Service found that effective workplace learning had three characteristics: it involved problem solving, occurred through group work and had the support of management. ${ }^{1}$ Problem-based learning (PBL) is well established in undergraduate and medical education, where it has been demonstrated to develop problem solving skills, critical thinking, teamwork and an ability to deal with complexity. Schmidt has shown that it helps medical students to acquire competencies relevant to professional practice. $^{2}$

Two articles 'Problem-based learning in public health workforce training: a discussion of educational principles and evidence' and 'Using problem-based learning in public health service based training' examine PBL methods and their potential application to workplace learning. Together these articles seek to answer whether PBL can be applied in postgraduate public health education that is delivered within the service environment.
Trevena reviews the literature describing the use of PBL in health education, and public health education in particular. Despite the benefits and growing application of PBL in health education there is a scarcity of literature describing its application in public health, particularly at the postgraduate level. This paper was used to inform discussions to develop a PBL approach for the NSW Public Health Officer Training Program. Heading, Lyle, Fuller and Madden describe an outcome of these discussions, a PBL workshop developed by The Broken Hill University Department of Rural Health in partnership with public health professionals from the Greater Western Area Health Service and the Training Program. The evaluation of this workshop found that participants like this way of working and learning. These findings were applied to a second PBL workshop for the Training Program, developed by the Northern Rivers University Department of Rural Health and public health professionals from the North Coast Area Health Service.

There is a growing appreciation of the potential contribution that telehealth can make to education, training, mentoring and administrative functions for public health. The use of communication technologies offers one way to increase equity of access to learning opportunities between locations and in particular for isolated practitioners in rural and remote settings. Twenty-six percent of the NSW population live in rural and remote areas and these populations generally have lower health status than the rest of NSW. The NSW Telehealth Initiative was established in 1996 to improve access to health services for these people. Since then it has sought to both expand existing services and encourage innovation in the application of the technologies to support the health of the people of NSW. The NSW Telehealth Initiative is now one of the largest 